\title{
El ASENTAMIENTO CALCOLítico del CERRO De LOS Estiles (ACEBUCHAL, BADAJOZ)
}

Los primeros trabajos arqueológicos en la finca de Los Estiles (Aceuchal, Badajoz) (fig. 1) se remontan a finales del año 2009, cuando el Ayuntamiento de Almendralejo plantea la adecuación y reforestación de este espacio periurbano dentro de las actividades de minimización de impacto arqueológico que consistió en una prospección arqueológica superficial.

En el transcurso de la prospección de esta zona se registraron indicios que apuntaban a la existencia de un asentamiento prehistórico en la zona de mayor elevación de la finca. En concreto, donde actualmente se localizan unas instalaciones deportivas de tiro al plato. Posteriormente en 2013 se efectuaron unos sondeos arqueológicos dentro del proyecto "Recuperación, protección, estudio y difusión de yacimientos arqueológicos en la comarca Sierra Grande-Tierra de Barros".

\section{LAS INTERVENCIONES ARQUEOLÓGICAS}

Se han desarrollado dos campañas de intervenciones arqueológicas en el yacimiento, la prospección arqueológica superficial de 2009 y la campaña de excavaciones de 2013.

\section{PROSPECCIÓN SUPERFICIAL (2009)}

Se abarcó de forma intensiva una superficie aproximada de dos hectáreas. El terreno se encontraba muy alterado por roturaciones contemporáneas y en gran medida por la construcción de un recinto deportivo de tiro al plato. Como consecuencia de las roturaciones modernas, se pudieron registrar en superficie materiales de clara tipología prehistórica. Estos restos se encontraban especialmente concentrados en la zona Oeste, en dos acumulaciones de tierra procedentes de una remoción efectuada para la construcción del foso del tiro al plato; entre los restos prehistóricos hallados cabe destacar algún fragmento de cerámica campaniforme, una pesa de telar y molinos de mano.

En la zona central del cerro, alrededor del foso y los puestos de la pista deportiva, se hallaron gran cantidad de fragmentos de cerámica a mano así como elementos líticos (láminas de sílex, molinos de mano, molederas). Aquí se observaban algunas piedras de gran tamaño que emergían en la superficie, en algunos casos alineadas.

$\mathrm{Al} \mathrm{N}$ de la zona elevadas se pudo observar un desnivel o pequeño escalón en el terreno, con una clara tendencia circular y una acumulación de grandes bloques de piedra 


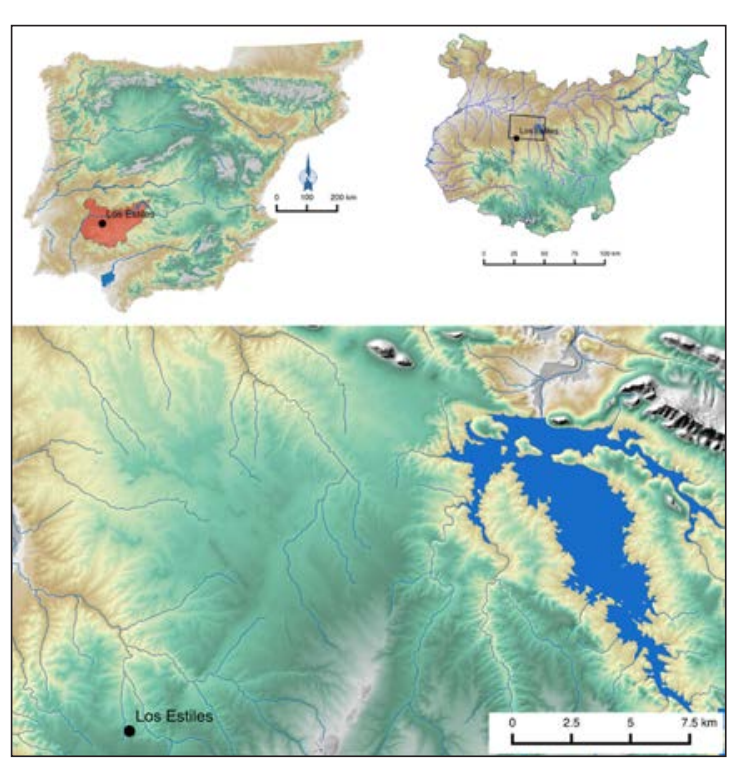

Fig. 1. Localización del yacimiento Los Estiles.

que diferenciaba la zona amesetada de la suave caída natural del cerro. Ello sugería algún tipo de sistema de cerramiento, que podría, como en otros casos conocidos en el territorio, corresponderse con un sistema de fortificación.

La distribución de materiales arqueológicos en superficie junto con la delimitación de tendencia circular marcada en el relieve por el escalón, estarían evidenciando la existencia de un muro de cerramiento de alrededor de media hectárea de extensión.

Para intentar definir la estructura, tipo y extensión del asentamiento se recurrió a un análisis de la microtopografía del terreno. Para ello se generó un MDT al que le hemos añadido una capa con el cálculo del ángulo de la pendiente en grados para cada celda basado en la primera derivada del MDT (Conolly y Lake 2006). Este análisis proporciona una visión del terreno en la que se pueden apreciar claramente dos círculos concéntricos en la zona amesetada del Cerro de los Estiles, el primero con una extensión aproximada de $0,5 \mathrm{Ha}$ y el segundo con una extensión de c. 1 ha (fig. 2).

El círculo de mayor extensión coincide con el resalte apreciado en el terreno, mientras que el de menor extensión coincide con una acumulación de piedras de tendencia circular que es inapreciable a simple vista. Estos indicadores microtopográficos nos estarían indicando la existencia de dos estructuras circulares que probablemente se correspondan con un sistema de murallas.

\section{EXCAVACIÓN ARQUEOLÓGICA (2013)}

Se practicaron cuatro sondeos en dos sectores del yacimiento con el objetivo de obtener una delimitación perimetral del yacimiento y comprobar si efectivamente los resaltes detectados en el terreno durante las prospecciones y el análisis de la microtopografía se correspondían con un sistema de murallas. Para ello, en la zona septentrional del asentamiento se hacen tres sondeos perpendiculares al resalte del terreno. En el centro del cerro se realiza un cuarto sondeo coincidiendo con la zona de mayor acumulación de materiales arqueológicos en superficie y con el segundo círculo detectado en el análisis de la microtopografía (fig. 2).

\section{RESULTADOS}

\section{LA EXTENSIÓN DEL ASENTAMIENTO}

En las prospecciones ya se observaba en superficie la existencia de un escalón formado por una alineación de piedras en el borde norte de la plataforma amesetada. La excavación de los cortes D y C (fig. 3) dispuestos perpendicularmente sobre dicho escalón permitió comprobar que se trataba de un muro de c. $0.8 \mathrm{~m}$ de ancho formado por piedras de mediano tamaño careadas y que interpretamos como un amurallamiento, éste delimitaría perimetralmente el asentamiento. La existencia de algunas piedras en la superficie señalarían su extensión a lo largo de todo el escalón detectado en superficie coincidiendo con el circulo exterior detectado en el análisis de la microtopografía.

Estas estructuras murarias delimitarían el perímetro del asentamiento, coincidiendo además con el resalte o escalón que se aprecia en la superficie del terreno y con la dispersión de materiales en superficie. Teniendo en cuenta estos datos calculamos que el asentamiento tendría una extensión de entre 0.8 y $1 \mathrm{Ha}$. Se correspondería con el tamaño de la mayor parte de los pequeños poblados calcolíticos localizados en este territorio (Hurtado 2000)

\section{¿UN RECINTO INTERIOR?}

En el corte B, situado en el centro del asentamiento se localizó un muro (UE 4) más ancho que los muros de los cortes C y D (perímetro del recinto) con una orientación NE-SO. La técnica constructiva que utiliza es diferente a la de los muros perimetrales ya que presenta un relleno interior entre las dos caras del muro (fig. 3). 


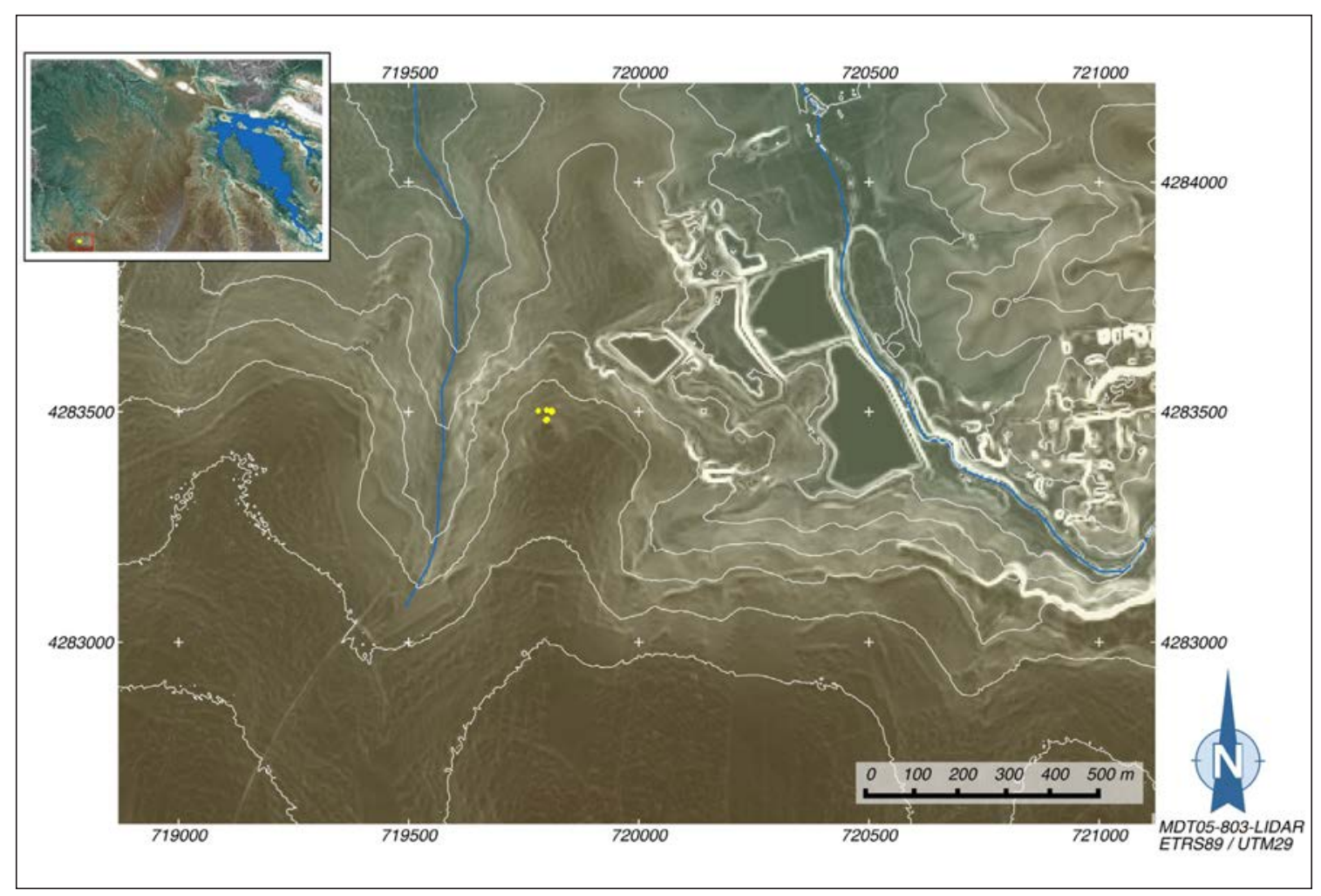

Fig. 2. MDT con el cálculo del ángulo de la pendiente, donde pueden apreciarse dos círculos concéntricos en la zona amesetada del Cerro de los Estiles. Los puntos marcan los sondeos llevados a cabo en 2013.

Las otras estructuras adosadas o próximas al muro UE4 resultan difíciles de interpretar. Es posible que la construcción adosada a la cara norte del muro pudiera corresponder al arranque de un bastión (UE 9), pero resulta difícil de pronunciarse, como también sobre el estrecho muro UE5. En otros asentamientos amurallados próximos, a las murallas se le adosan estructuras semicirculares de tipo bastión. Este sistema de muralla y bastión se suele reforzar con un muro que discurre paralelo al lienzo de muralla. Entre ambos muros se practica un relleno de tierra compactada que en algunas ocasiones se fortalece con piedras de pequeñas dimensiones o guijarros.

$\mathrm{Al}$ interior del muro UE4 se hallaron otras construcciones de tendencia circular; la más evidente es la formada por la UE7, un muro que dibuja un arco mediante una línea de piedras y que delimita un espacio de tierra oscura y pequeñas piedras que contenía la mayor acumulación de cerámica registrada en la excavación y que incluye dos fragmentos campaniformes.

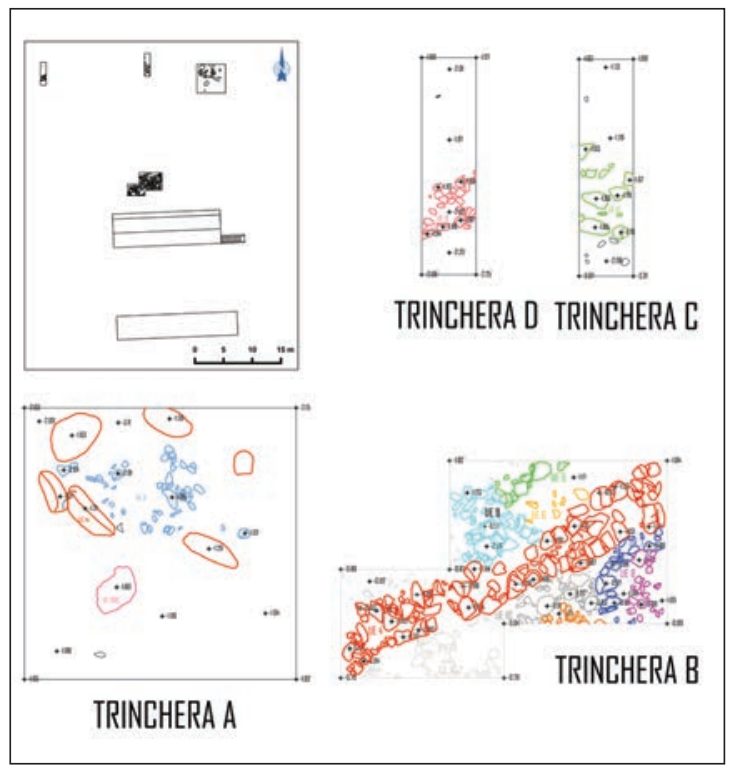

Fig. 3. Planimetría de la excavación. 


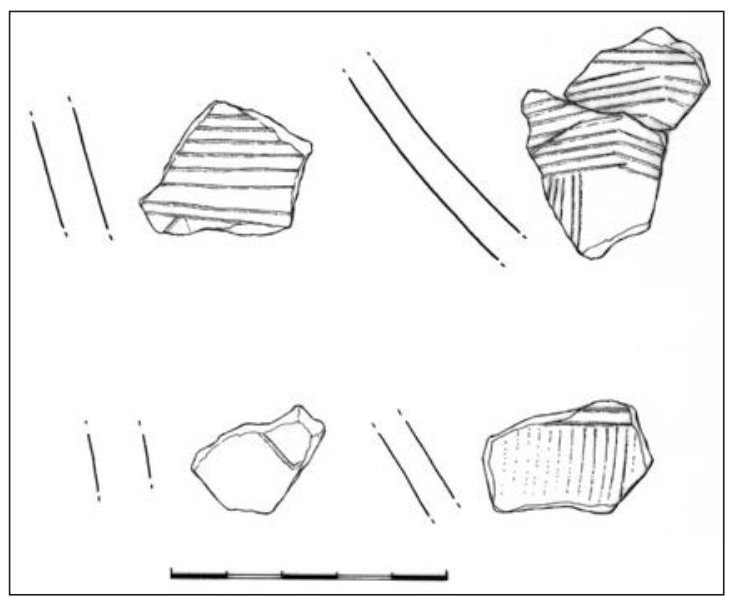

Fig. 4. Cerámica campaniforme recuperada durante las excavaciones.

\section{CULTURA MATERIAL}

El material arqueológico recuperado en ambas campañas es mayoritariamente cerámico, destacando la presencia de alguna lámina tallada y la ausencia de artefactos metálicos y óseos. La cultura material registrada en la campaña de excavación se corresponde con el último momento de uso del espacio en época prehistórica, justo antes de su abandono.

La mayor parte del material registrado consiste en cerámica a mano, además de los platos modernos utilizados para el tiro con escopeta. El repertorio cerámico del Cerro de los Estiles está mayoritariamente compuesto por bordes entrantes, aunque también están representados los recipientes abiertos o cuencos hemisféricos. La mayoría de estos ejemplares presentan una superficie bruñida o alisada, a excepción de los ejemplos de decoración incisa perteneciente a la cerámica decorada anteriormente descrita (fig. 4).

En la tipología cerámica llama la atención la escasa presencia del plato de borde engrosado, tan solo se halló un fragmento en superficie, en el transcurso de la prospección.

Lo más significativo de este material se refiere a los fragmentos decorados. Se recuperaron 10 fragmentos de cerámica decorada, entre ellos seis fragmentos campaniformes.

La proporción de hallazgos de cerámica campaniforme resulta relevante si tenemos en cuenta el poco espacio excavado y su limitada presencia respecto al volumen total de cerámica registrada en otros yacimientos de la región. Otro hecho destacable es que la presencia de la cerámica campaniforme se encuentra en los cortes A y B donde se han identificado las estructuras de tendencia circular posiblemente de carácter habitacional.

La cerámica campaniforme de estilo continental se puede encuadrar en el arco temporal de la segunda mitad del III milenio ANE (Vander Linden 2006). Así pues este tipo de decoración nos permitiría situar este nivel de ocupación en la segunda mitad del III milenio ANE.

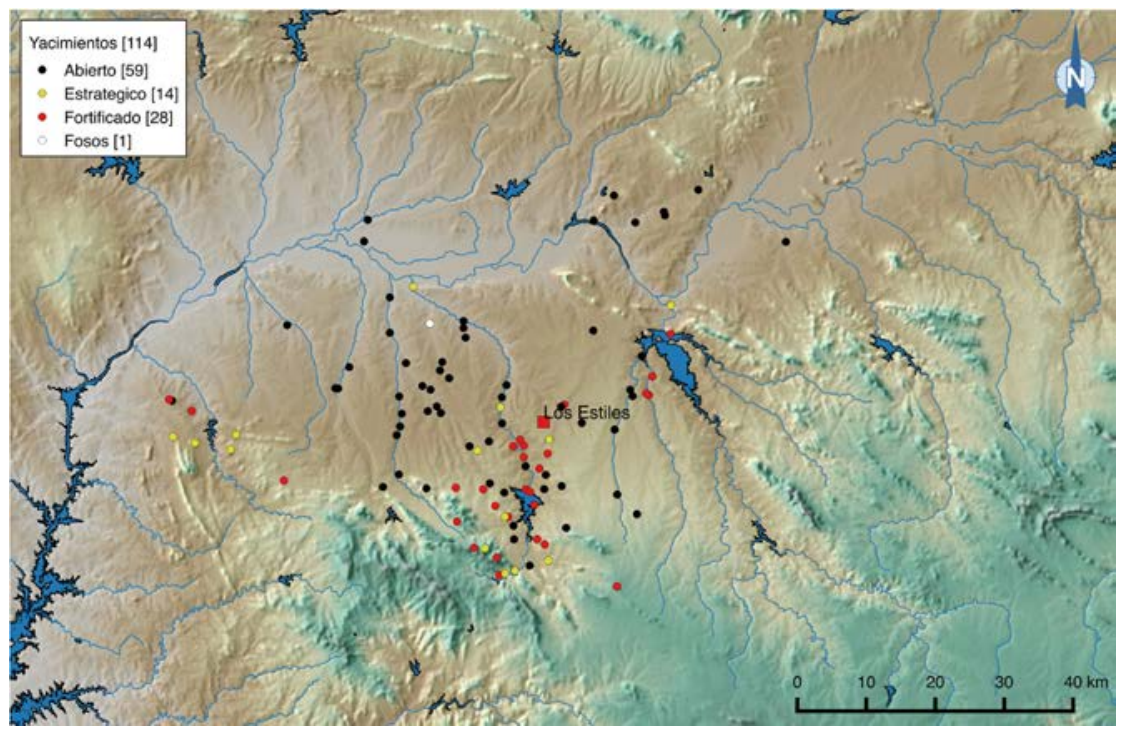

Fig. 5. Territorio de Tierra de Barros (después de Hurtado y Mondejar 2008) con indicación de la ubicación de Los Estiles en el territorio. 


\section{EL ASENTAMIENTO PREHISTÓRICO DEL CE- RRO DE LOS ESTILES EN EL CONTEXTO DE TIERRA DE BARROS}

Las prospecciones realizadas en la Vega de Harnina vienen a confirmar junto con el nuevo hallazgo de Los Estiles la importancia que tuvo el poblamiento en esta área durante el calcolítico con una alta densidad de pequeños asentamientos abiertos en llano o suaves lomas localizados junto a la confluencia de cursos de agua como se detecta en la zona baja de Cabezo San Marcos: (Huerta Zacarías-Los Cañitos), en los Altos de Cuéllar o en el Cortijo del Marqués de la Encomienda junto al arroyo Santa Lucía, entre otros.

El principal interés que aporta el hallazgo de este yacimiento es que se encuentra entre otras fortificaciones que en su conjunto forman una línea en sentido Norte-Sur desde el río Guadiana hasta la cadena montañosa de la Sierra del Castellar en Zafra limitando de esta manera por el Este el espacio de la comarca de Tierra de Barros (fig. 5) (Hurtado y Mondejar 2008).

Se trataría de un territorio jerarquizado de acuerdo al modelo propuesto por Hurtado (1995): por un lado, en el centro de un paisaje de características fisiográficas muy homogéneas y delimitado geográficamente por barreras naturales donde se encuentran una serie de pequeños asentamientos abiertos de menos de $1 \mathrm{Ha}$ de extensión -ubicados siempre junto a manantiales y arroyos; por otro lado, al Este el paisaje continúa siendo llano y sin delimitación geográfica notable y es precisamente en este sector del territorio donde se concentra un grupo de poblados amurallados cuya alineación en sentido Norte-Sur (entre Mérida, Almendralejo y Zafra) podrían constituir una delimitación artificial del lado oriental (Hurtado 1995). Esta línea de fortificaciones delimita el paisaje separando los terrenos fértiles del lado occidental de otros suelos, al Este, más apropiados para pastos; los poblados amurallados aprovechan los enclaves algo más elevados de la orografía o pequeñas terrazas para asentarse. La mayor parte de ellos se concentran en el ángulo Sureste del paisaje, donde el terreno está formado por suaves montículos que permiten cierto control visual de la zona.

Dentro de este panorama, el asentamiento amurallado del Cerro de los Estiles, estaría formando parte de esta red de poblamiento del III milenio ANE en Tierra de Barros, en concreto participando de ese entramado 'defensivo' que delimita el paisaje por el sector oriental (fig. 5). El Cerro de los Estiles vendría a aproximar un área que habíamos considerado vacía en la disposición del alineamiento y visibilidad de las fortificaciones concretamente el espacio comprendido entre los sitios de Cabezo San Marcos (Almendralejo) y Cabezo Las Pilas o Cerro de la Cruz (Aceuchal), ahora conectados entre sí por medio de este nuevo sitio.

Carlos P. Odriozola Dpto. de Prehistoria y Arqueología Universidad de Sevilla codriozola@us.es

Jesús Moreno García Aequeas. Gestión integral del Patrimonio jmhistoriador@gmail.com

Victor Manuel Hurtado Pérez Dpto. de Prehistoria y Arqueología Universidad de Sevilla vhurtado@us.es

\section{BIBLIOGRAFÍA}

CONOLLY, J.; LAKE, M. (2006): Geographical Information Systems in Archaeology, Cambridge.

HURTADO, V. (1995): Interpretación sobre la dinámica cultural en la Cuenca Media del Guadiana (IV-III milénios ANE), Extremadura Arqueológica V. 53-80.

HURTADO, V. (2000): El proceso de transición a la Edad del Bronce en la Cuenca Media del Guadiana. Ruptura o continuidad, Actas do 3 o Congresso do Arqueología peninsular, Porto, 381-398.

HURTADO, V.; MONDEJAR, P. (2008): Prospecciones en Tierra de Barros (Badajoz). Los asentamientos del III milenio a.n.e., Estudios de Prehistoria y Arqueología en homenaje a Pilr Acosta Martínez (R. Cruz-Auñón y E. Ferrer, eds.), Sevilla, 187-206.

VANDER LINDEN, M. (2006): Le phénomène campaniforme dans l'Europe du 3ème millénaire avant notre ère: synthèse et nouvelles perspectives. Oxford. 